\title{
Study on Permeability Change Rule of Different Rank Coals by Injecting Carbon Dioxide
}

\author{
Hui Guo*, Ye Chen, Xiangdong Gao \& Chuanqi Tao \\ College of Geoscience and Surveying Engineering, China University of Mining and Technology (Beijing), Bei- \\ jing, China
}

\begin{abstract}
This paper provides an experimental support for increasing the flow conductivity of coal reservoir by identifying permeability change rule caused by reactions with different minerals in coal after injecting carbon dioxide. Based on measurement of nitrogen adsorption, mineral composition and permeability of medium-high rank coal in Tunlan mine and Sihe mine, it is used to investigate the permeability change rule caused by reactions with different minerals in coal and its improving effect after injecting carbon dioxide. A permeability change model was established by making a nonlinear regression analysis of the initial permeability, the reaction time and the improved permeability. The results showed that as a result of $\mathrm{CO}_{2}$-water-rock interaction, permeability of medium-high rank coal increases at first and then decreases with time going by after injecting carbon dioxide. The permeability of Sihe coal samples reaches maximum value earlier than that of Tunlan coal samples. Improving effect of permeability of Sihe coal samples is better than that of Tunlan coal samples. The initial permeability which is too large or too small is insensitive to the change of permeability, while the medium permeability within $0.1--0.2 \times 10^{-3} \mu \mathrm{m}^{2}$ is more favorable. The reliability of the mathematical model is verified by the experiment. The results can also provide a theoretical basis for the analysis of permeability change after injecting carbon dioxide.
\end{abstract}

Keywords: coal bed methane; permeability; minerals; injection of $\mathrm{CO}_{2}$

\section{INTRODUCTION}

The low permeability of coal seam is the main bottleneck of our coal bed methane (CBM) development, resulting in low gas production rate of the CBM wells and low development of CBM industry in China. According to the characteristics that the coal adsorption capacity of $\mathrm{CO}_{2}$ is higher than $\mathrm{CH}_{4}$, methane adsorped in coal bed is replaced ${ }^{[1,2]}$. Thus injecting $\mathrm{CO}_{2}$ to deep coal seam can not only reduce greenhouse gases, but also enhance methane recovery rate ${ }^{[3-5]}$, and it has important practical significance in CBM development. Some researchers found that the pores and fractures are usually filled with minerals, the connectivity between them is poor ${ }^{[6-8]}$, and as a result, it will affect permeability. It causes matrix swelling, mineral dissolution and precipitation after injecting $\mathrm{CO}_{2}$ to coal seam, and then the flow conductivity of coal reservoir is changed ${ }^{[9]}$. The research on permeability change law after $\mathrm{CO}_{2}$ injection into coal seam plays an important role in guiding the exploitation. The coalbed methane recovery rate of anthracite in Qinshui basin has been enhanced by injecting $\mathrm{CO}_{2}{ }^{[10]}$, so it has an important practical significance to take the coal seam in Qinshui basin as the research object. Some scholars found that the permeability of the coal samples increased in different degree by way of laboratory experimental study on injecting $\mathrm{CO}_{2}$ to coal samples ${ }^{[11 \text {, }}$ ${ }^{12]}$. But there is little research on influence of interaction among $\mathrm{CO}_{2}$, water and minerals, and long-term *Corresponding author: guohui117@126.com change laws of permeability of medium-high rank coals sample after injecting $\mathrm{CO}_{2}$. In order to explore permeability change rules, the author tested the variation of the permeability of the coal samples from Sihe and Tunlan mine before and after acidification and summed up the rules, hoping to provide technical support for CBM development of medium and high rank coal.

\section{COAL SAMPLES AND EXPERIMENTAL METHOD}

The coarse coal samples of this experiment are collected from No. 3 coal seam of shanxi formation of lower Permian of Sihe mine in Jincheng and Tunlan mine in Taiyuan. They are respectively anthracite and coking coal. Four cylindrical coal samples were drilled from every mining area, processing to cylinders with the diameter of $25 \mathrm{~mm}$ and $50 \mathrm{~mm}$ in height, which are labeled as SH1-SH4 and SQ1-SQ4. Results of coal quality analysis and mineral composition analysis of coal samples are respectively shown in Table 1 and Table 2. According to the result of nitrogen adsorption measurement as shown in Table 3, the pores of Shaqv and Sihe coal samples mainly consist of transitional pores and mesopores. The total volume percentage of macropore $(>50 \mathrm{~nm})$, mesopore $(2--50 \mathrm{~nm})$ and micropore $(<2 \mathrm{~nm})$ of Shaqv coal samples is respectively $67.1 \%, 32.4 \%$ and $0.5 \%$,whereas 


\section{MATEC Web of Conferences}

Sihe coal samples is $25.5 \%, 63.7 \%$ and $10.8 \%$. BJH total pore volume of Shqv and Sihe coal samples is respectively $0.00179 \mathrm{~cm}^{3} / \mathrm{g}$ and $0.00636 \mathrm{~cm}^{3} / \mathrm{g}$, and BET surface area is respectively $0.5311 \mathrm{~m}^{2} / \mathrm{g}$ and $11.337 \mathrm{~m}^{2} / \mathrm{g}$. Compared with the coal samples of Shaqv, the pores of Sihe coal samples are developed better.

In order to study permeability change rule of coal samples after acidification, following experiments were conducted: Put plenty of dry ice into mine water which was taken from SX-001 well of Shizhuang north block in southern Qinshui basin $(\mathrm{PH}=8.3)$, and prepare saturated aqueous solution of $\mathrm{CO}_{2}(\mathrm{PH}=6.3)$, then let coal samples from the two mining areas fully respond with the saturated acid solution. Test the porosity and permeability of coal column samples under different reaction time with AP-608 automated permeameter-porosimeter to get the change laws of the permeability with reaction time.

Table 1 . Results of coal quality analysis (\%)

\begin{tabular}{lllll}
\hline Samples & $\mathrm{M}_{\mathrm{ad}}$ & $\mathrm{A}_{\mathrm{ad}}$ & $\mathrm{V}_{\mathrm{ad}}$ & $\mathrm{R}_{\max }$ \\
\hline Shaqv & 5.46 & 10.75 & 12.11 & 1.62 \\
Sihe & 1.01 & 11.00 & 12.01 & 2.15
\end{tabular}

\section{RESULTS AND DISCUSSION}

\subsection{Permeability change rule of medium-high rank coal with time}

Due to the character of soluble mineral dissolution, new mineral precipitation and expansion of clay mineral, physical property of coal changes constantly. In acidic aqueous media of $\mathrm{CO}_{2}$, carbonate minerals, including calcite and dolomite, can be dissolved to some extents and have positive effect on permeability. Carbonate minerals content plays a decisive role in physical property change. Precipitation of kaolinite is formed by the reaction of chlorite with $\mathrm{CO}_{2}$ solution. Montmorillonite and illite expand when water goes in, then the produced side chains fall off, blocking pore throat. They all have negative effect on permeability. Potassium feldspar reacts with $\mathrm{CO}_{2}$ solution, producing precipitation of kaolinite; partial potassium feldspar dissolves, causing positive and negative effects. At the beginning of the treatment, ion-exchange of minerals with acid solution is active, and it tends to be equilibrium with time.

The permeability of rock and coal all increased first and then decline with time. According to the fitting calculation for the permeability of coal sample from Shaqv and Sihe mine shown in Figure 1, the average of maximum permeability of coal samples in Shaqv is $0.17 \times 10^{-3} \mu \mathrm{m}^{2}$ and the time span is 4.11 months after the acidification process. The average of maximum permeability in Sihe mine is $2.80 \times 10^{-3} \mu \mathrm{m}^{2}$ and the time span is 3.68 months. Thus the permeability of coal sample in Sihe reaches the maximum first, while the coal sample in Shaqv lags behind after the acidification process. Due to heterogeneity and maturity of coal, the initial permeability of coal samples is different in the same district. In general, initial permeability of coal sample in Shaqv is lower than Sihe. The reason for the difference in maximum permeability value and the time for coal samples in Sihe and Shaqv mine after acid treatment is that the initial permeability, mineral composition and pore characteristics are diverse in different coal samples.

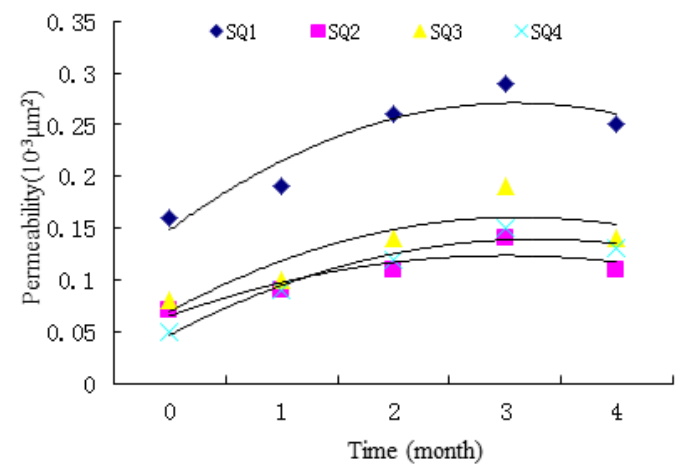

(a) Coal samples of Shaqv mine

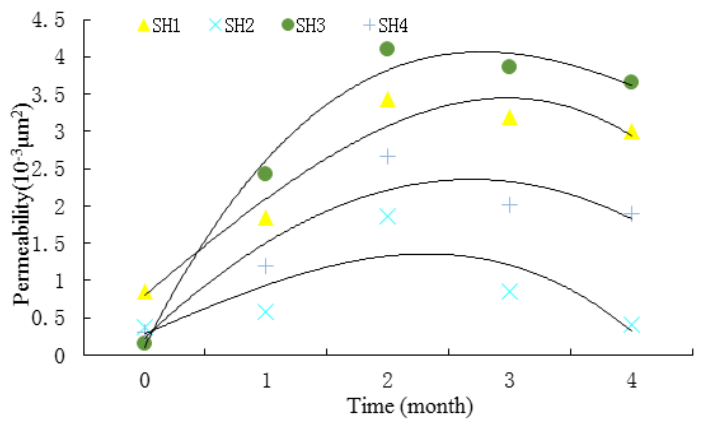

(b) Coal samples of Sihe mine

Figure 1. Permeability change rule of Shaqv and Sihe coal samples with time

During the initial stage of acidification, the reaction of carbonate minerals with acid solution is very active. Clay minerals get expansion rapidly in water. However, due to the mine water salinity of $2.1 \mathrm{~g} / \mathrm{L}$, it will produce swelling inhibition effect ${ }^{[13]}$, which makes the positive effect play a dominate role and permeability increase. The content of minerals involved into the dissolution reaction accounts for $2 \%$ of the total rock in Shaqv coal sample, while the coal sample in Sihe reaches $12 \%$. Therefore, the reaction of carbonate minerals is more active in Sihe coal sample, which connects the fractures in coal and then increases the permeability. The clay mineral content of Shaqv coal samples is $93 \%$ of total rock minerals, which is higher than coal samples of Sihe. Among them, the mineral content of illite accounts for $17 \%$ of total rock minerals, illite swells in water, clogging the pore throat, 
EMME 2015

Table 2. Analysis and test results of mineral composition by means of XRD (\%)

\begin{tabular}{llllllllll}
\hline Samples & Calcite & $\begin{array}{l}\text { Potassium } \\
\text { feldspar }\end{array}$ & Dolomite & Quartz & Kaolinite & Chlorite & $\begin{array}{l}\text { Montmoril- } \\
\text { lonite }\end{array}$ & Illite & Hematite \\
\hline Shaqv & 0 & 0 & 2 & 2 & 70 & 0 & 6 & 17 & 3 \\
Sihe & 5 & 1 & 7 & 9 & 3 & 13 & 35 & 27 & 0 \\
\hline
\end{tabular}

Note: The minerals of coal samples in Shaqv and Sihe contain illite-montmorillonite interstratified minerals and chlorite-montmorillonite interstratified minerals, and both are converted to individual minerals.

Table 3. Pore structure parameters for the coal samples by N2 adsorption isotherms

\begin{tabular}{lllllll}
\hline Samples & $\mathrm{D}^{\mathrm{a}}(\mathrm{nm})$ & $\mathrm{V}_{\text {Micro }}\left(\mathrm{cm}^{3} / \mathrm{g}\right)$ & $\mathrm{V}_{\text {Meso }}{ }^{\mathrm{c}}\left(\mathrm{cm}^{3} / \mathrm{g}\right)$ & $\mathrm{V}_{\text {Macro }}{ }^{\mathrm{d}}\left(\mathrm{cm}^{3} / \mathrm{g}\right)$ & $\mathrm{V}_{\text {Total }}{ }^{\mathrm{e}}\left(\mathrm{cm}^{3} / \mathrm{g}\right)$ & $\mathrm{S}_{\mathrm{BET}}^{\mathrm{f}}\left(\mathrm{m}^{2} / \mathrm{g}\right)$ \\
\hline Shaqv & 145.78 & 0.00000856 & 0.000578 & 0.00120 & 0.00178 & 0.5311 \\
Sihe & 34.47 & 0.000686 & 0.00405 & 0.00162 & 0.00635 & 11.337 \\
\hline
\end{tabular}

${ }^{\mathrm{a}}$ Average pore diameter $(\mathrm{nm}): 2 \times \mathrm{S}_{\mathrm{BET}} / \mathrm{V}_{\mathrm{ads}} .{ }^{\mathrm{b}}$ Micropore volume $\left(\mathrm{cm}^{3} / \mathrm{g}\right)$ : Dubinin-Radushkevich equation.

${ }^{c}$ Mesopore volume $\left(\mathrm{cm}^{3} / \mathrm{g}\right):$ BJH equations. ${ }^{d}$ Macropore volume $\left(\mathrm{cm}^{3} / \mathrm{g}\right):$ BJH equations. ${ }^{\mathrm{e}}$ Total pore volume $\left(\mathrm{cm}^{3} / \mathrm{g}\right)$ : BJH equations. Specific surface area $\left(\mathrm{m}^{2} / \mathrm{g}\right)$ : BET equation $\left(\mathrm{P} / \mathrm{P}_{0}=0.01--0.994\right)$.

Table 4. Effect analysis of improvement on permeability of Shaqv and Sihe coal samples

\begin{tabular}{lllll}
\hline Coal sample & $\begin{array}{l}\text { Initial permeability } \\
\left(10^{-3} \mu \mathrm{m}^{2}\right)\end{array}$ & $\begin{array}{l}\text { Maximal variation of per- } \\
\text { meability }\left(10^{-3} \mu \mathrm{m}^{2}\right)\end{array}$ & $\begin{array}{l}\text { Change rate of maxi- } \\
\text { mum permeability }(\%)\end{array}$ & $\begin{array}{l}\text { Ultimate permea- } \\
\text { bility }\left(10^{-3} \mu \mathrm{m}^{2}\right)\end{array}$ \\
\hline SQ1 & 0.16 & 0.13 & 81 & 0.25 \\
SQ2 & 0.07 & 0.07 & 100 & 0.11 \\
SQ3 & 0.08 & 0.11 & 137 & 0.14 \\
SQ4 & 0.05 & 0.10 & 200 & 0.13 \\
SH1 & 0.86 & 2.58 & 300 & 3.00 \\
SH2 & 0.37 & 1.49 & 292 & 0.41 \\
SH3 & 0.15 & 3.95 & 2633 & 3.66 \\
SH4 & 0.30 & 2.37 & 790 & 1.90 \\
\hline
\end{tabular}

Note: Change rate of maximum permeability: $\mathrm{S}=\frac{(P 2-P 1) \cdot 100}{P 1}, \mathrm{P} 1$ and $\mathrm{P} 2$ respectively denote the initial permeability and the ultimate permeability.

thereby reducing the permeability. The Kaolinite is more stable in acid solution ${ }^{[14]}$. The montmorillonite content is $35 \%$ of total rock mineral in Sihe coal samples, but the increasing rate of permeability is still high at the first three months. It may be caused by the possibility that aqueous solution of $\mathrm{CO}_{2}$ flows along the way with a better permeability, which makes the clay minerals less with the flowing water. The clay minerals increase where the permeability is worse, blocking the throat more easily. When permeability reaches the maximum value after acidification process, the permeability trend will decline, but it varies within a small range. It may be caused by the exhausted carbonate minerals, the exfoliated side chain after swelling of clay minerals and the precipitation of silicate minerals.

\subsection{Effect analysis of improvement on permeability of medium-high rank coal}

Due to different initial permeability, mineral composition and content of coal sample in Shaqv and Sihe, the permeability change laws are different in these two districts after acidification treatment with some different improvement effects. As shown in Table 4, the higher the initial permeability is, the larger the maximal variation of permeability is. It indicates that acid solution can easily react with more minerals with the increasing initial permeability, which leads more dissolved minerals and has a good effect of enlarging pore and dredging pore throat. The higher the initial permeability is, the higher the ultimate permeability after improvement can be. By fitting initial permeability with change rate of maximum permeability, as shown in Figure 2, the change rate of maximum permeability first increases and then decreases with the initial permeability increase. The coefficient of determination $\left(R^{2}\right)$ is 0.64 . The results show that the initial permeability which is too large or too small will lead to a low change rate of maximum permeability. Only when permeability is in range of $0.1--0.2 \times 10^{-3} \mu \mathrm{m}^{2}$ can the change rate of maximum permeability be higher, leading a good improvement effect after acidification process.

It is shown that the permeability of coal sample in Shaqv and Sihe all becomes higher after $\mathrm{CO}_{2}$ acidizing fluid treatment. But the improvement effect of permeability in Sihe mine is better. The reason for this phenomenon is that the mineral content of coal samples in Sihe is higher than Shaqv. What's more, the content of carbonate minerals which can react easily with $\mathrm{CO}_{2}$ acidizing fluid is higher. After reaction with acid fluid, minerals filled in pores and fractures will be corroded, causing permeability increasing more quickly. BET surface area of coal sample in Sihe is bigger, so the contact area reacting with acid solution is larger, which is also the reason for a large increase in permeability. The coal sample in Sihe has the character of rich fracture and high initial permeability with a good acidification effect. While the coal samples in 


\section{MATEC Web of Conferences}

Shaqv have undeveloped crack and low initial permeability with a non-ideal acidification effect.

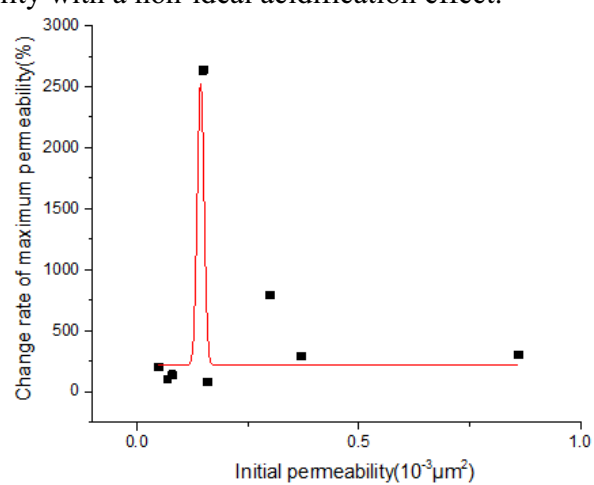

Figure 2. Correlation between initial permeability and change rate of maximum permeability

\subsection{Nonlinear regression model of permeabilit change after reaction of Minerals in coal with $\mathrm{CO}_{2}$ solution}

The data of initial permeability, permeability changed with time after acidization and acidizing time are analyzed by SPSS software. According to fitting results in Figure 1, permeability model of initial permeability and time is obtained by regress analysis, considering the effect of initial permeability on coefficient. The model of permeability in Shaqv mine is described by the following function:

$\mathrm{K}_{1}=\left(\mathrm{aK}_{0}^{2}+\mathrm{bK}_{0}+\mathrm{c}\right) \mathrm{T}^{2}+\left(\mathrm{dK}_{0}^{2}+\mathrm{eK}_{0}+\mathrm{f}\right) \mathrm{T}+\mathrm{g}$

Where $\mathrm{K}_{1}$ denotes permeability after acidization at each time point; $\mathrm{K}_{0}$ denotes initial permeability; $\mathrm{T}$ denotes the time points, and a, b, c, d, e, f and g denote coefficients.

With the results of nonlinear regression analysis, the estimated value of coefficient is obtained as shown in Table 5. There was good relativity, and the correlation coefficient is $0.976(\mathrm{P}<0.01)$.

The results of comparison between predicted and experimental permeability are shown in Figure 3, and coefficient of correlation $\left(\mathrm{R}^{2}\right)$ is 0.949 . In a certain degree, the results show that the accuracy of the model is verified.

Table 5. Results concerning estimated value of coefficient in Shaqv mine

\begin{tabular}{lllll}
\hline \multirow{2}{*}{ Parameters } & Estimate & SE & \multicolumn{2}{c}{$95 \%$ Confidence Interval } \\
\cline { 4 - 5 } & & & Lower bound & Upper bound \\
\hline a & -0.814 & 1.904 & -5.121 & 3.493 \\
b & -0.020 & 0.419 & -0.967 & 0.927 \\
c & -0.009 & 0.020 & -0.053 & 0.036 \\
d & 5.868 & 6.540 & -8.927 & 20.663 \\
e & -0.194 & 1.438 & -3.447 & 3.060 \\
f & 0.069 & 0.069 & -0.088 & 0.226 \\
g & 0.024 & 0.024 & -0.031 & 0.079 \\
\hline
\end{tabular}

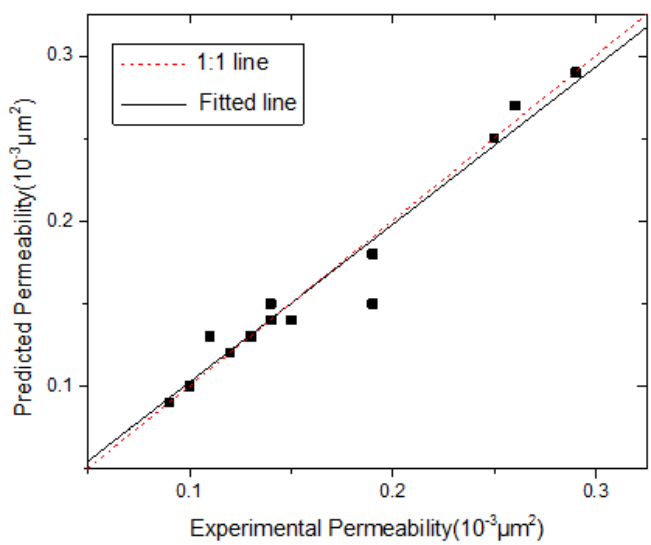

Figure 3. Correlation between predicted and experimental permeability of Shaqv mine

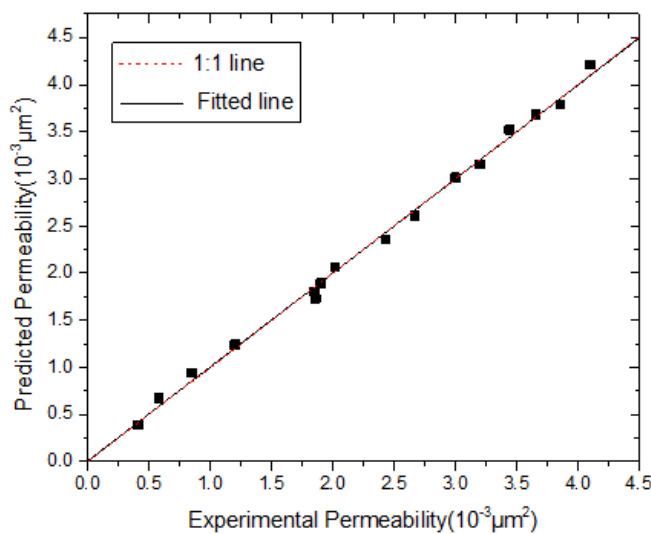

Figure 4. Correlation between predicted and experimental permeability of Sihe mine

In a similar way, the model of permeability in Sihe mine is described by the following function

$$
\begin{aligned}
& \mathrm{K}_{2}=\left(\mathrm{a}^{\prime} \mathrm{K}_{0}{ }^{\prime 3}+\mathrm{b}^{\prime} \mathrm{K}_{0}{ }^{\prime 2}+\mathrm{c}^{\prime} \mathrm{K}_{0}{ }^{\prime}+\mathrm{d}^{\prime}\right) \mathrm{T}^{\prime 3}+\left(\mathrm{e}^{\prime} \mathrm{K}_{0}{ }^{\prime 3}+\mathrm{f}^{\prime} \mathrm{K}_{0}{ }^{2}+\mathrm{g}^{\prime} \mathrm{K}_{0}^{\prime}+\mathrm{h}^{\prime}\right) \\
& \mathrm{T}^{\prime 2}+\left(\mathrm{i}^{\prime} \mathrm{K}_{0}^{\prime}{ }^{3}+\mathrm{j}^{\prime} \mathrm{K}_{0}^{\prime}{ }^{2}+\mathrm{k}^{\prime} \mathrm{K}_{0}^{\prime}+\mathrm{l}^{\prime}\right) \mathrm{T}^{\prime}+\mathrm{m}^{\prime}
\end{aligned}
$$

Where $\mathrm{K}_{2}$ denotes permeability after acidization at each time point; $K_{0}{ }^{\prime}$ denotes the initial permeability; $T^{\prime}$ denotes the time points, and a ',b ',c ',d ',e ',f', g ',h ',i ',j ',k ', 1 ' and $m$ ' denote coefficients.

The estimated value of coefficient is obtained as shown in Table 6. There was good relativity, and the correlation coefficient is $0.998(\mathrm{P}<0.01)$.

The results of comparison between predicted and experimental permeability are shown in Figure 4, and the coefficient of correlation $\left(\mathrm{R}^{2}\right)$ is 0.996 . In a certain degree, the results show that the accuracy of the model is verified. 
Table 6. Results concerning estimated value of coefficient in Sihe mine

\begin{tabular}{lllll}
\hline \multirow{2}{*}{ Parameters } & Estimate & SE & \multicolumn{2}{c}{$95 \%$ Confidence Interval } \\
\cline { 3 - 5 } & & & Lower bound & Upper bound \\
\hline a $^{\prime}$ & 2.444 & 8.636 & -25.039 & 29.927 \\
b $^{\prime}$ & -2.744 & 11.751 & -40.141 & 34.652 \\
c $^{\prime}$ & 0.534 & 4.202 & -12.839 & 13.908 \\
d $^{\prime}$ & 0.405 & 0.414 & -0.911 & 1.721 \\
e $^{\prime}$ & -11.886 & 50.715 & -173.285 & 149.513 \\
f' $^{\prime}$ & 10.952 & 69.009 & -208.666 & 230.571 \\
g ' $^{\prime}$ & 0.011 & 24.678 & -78.526 & 78.549 \\
h $^{\prime}$ & -3.933 & 2.444 & -11.712 & 3.846 \\
i $^{\prime}$ & 40.549 & 70.274 & -183.094 & 264.193 \\
j $^{\prime}$ & -37.064 & 95.625 & -341.385 & 267.257 \\
k' $^{\prime}$ & 0.090 & 34.197 & -108.741 & 108.921 \\
l' $^{\prime}$ & 10.692 & 3.479 & -0.379 & 21.762 \\
m $^{\prime}$ & -4.358 & 0.653 & -6.436 & -2.279 \\
\hline
\end{tabular}

\section{CONCLUSIONS}

Permeability change rule after reaction of minerals in medium-rank coals and high-rank coals with $\mathrm{CO}_{2}$ solution has been studied in this research. It is found that permeability of coal samples increases at first and then decreases with time after injecting $\mathrm{CO}_{2}$. Permeability of coal samples in Sihe mine reaches maximum of $2.8 \times 10^{-3} \mu^{2}$ after 3.68 months at first, then Shaqv mine of $0.17 \times 10^{-3} \mu^{2}$ after 4.11 months. The improvement effect of permeability in Sihe mine is better than Shaqv mine. It is due to higher initial permeability of coal samples in Sihe mine, more minerals will react with $\mathrm{CO}_{2}$ solution and rich fracture. Initial permeability which is too high or too low goes against the improvement effect. Only when initial permeability is in the range of $0.1--0.2 \times 10^{-3} \mu \mathrm{m}^{2}$ can the change rate of maximum permeability be relatively high with good acidizing effect. To some degree, a binary regression equation that could show the permeability change rule by treating with $\mathrm{CO}_{2}$ acid solution is set up, in which the initial permeability and acidizing time are used as independent variables.

\section{ACKNOWLEDGEMENT}

This work was supported by the National Science and Technology Major Projects (2011ZX05042-03, 2011ZX05034-05), which we gratefully acknowledge.

\section{REFERENCES}

[1] Tang, S.H. Yang, Q. Tang, D.Z. Shang, X.J. \& Wang, J. 2002. Study on the experiment and mechanism of raising the recovery ratio of coal bed methane by gas injection. Petroleum Geology \& Experiment 24(6): 545-549.

[2] Liang, W.G. Wu, D. \& Zhao, Y.S. 2010. Experimental study of coal beds methane replacement by carbon dioxide. Chinese Journal of Rock Mechanics and Engineering 29(4):665-673.

[3] Zuber, M.D. 1998. Production characteristics and reservoir analysis of coalbed methane reservoirs. International Journal of Coal Geology 38(1-2):27-45.

[4] Reznik, A.A. Aingh, P.K. \& Foley, W.L. 1984. Analysis of the effect of $\mathrm{CO} 2$ injection on the recovery of in-situ methane from Bituminous coal: an experimental simulation. SPE Journal 24(5):521-528.

[5] Tang, S.H. Ma, C.X. Ye, J.P. \& Wu, J.G. 2006. A modeling experiment of enhancing oalbed methane recovery by carbon dioxide injection. Journal of China University of Mining \& Technology 05:607-611+616.

[6] Gayer, R. \& Harris, I. 2006. Nature and origin of fracture in Permian coals from the Bowen Basin Queensland, Australia. Coal Bed Methane and Coal Geology 109: 133-150.

[7] Fu, X.H. Qin, Y. \& Wei, C.T. 2007. Coal bed gas geology. Xu zhou: China University of Mining and Technology Press.

[8] Tao, S. Wang, Y.B. Tang, D.Z. Xu, H. He, W. \& Li, Y. 2012. Pore and fracture systems and their contribution to the permeability of coal reservoirs in Southern Qinshui Basin. Geological Journal of China Universities 18(3):522-527.

[9] Gao, S.S. Wang, Y.B. Ni, X.M. Yuan, J. \& Wang, X.H. 2014. Study on laws of coal seam permeability change in CO2-ECBM. Coal Science and Technology 02:54-57+62.

[10]Ye, J.P. Zhang, B. \& Wong, S. 2012. Test of and evaluation on elevation of coalbed methane recovery ratio by injecting and burying $\mathrm{CO} 2$ for $3 \#$ coal seam of north section of Shizhuang, Qingshui Basin, Shanxi. Engineering Sciences 02:38-44.

[11]Jiang, W.P. \& Cui, Y.J. 2010. A discussion on main geologic controlling factors of $\mathrm{CO} 2$ sequestration in deep coal seams. Coal Geology of China 11:1-6.

[12] Yue, L.X. Sun, K.M. \& Hao, Z.Y. 2014. Study on increased permeability law of coal seam by supercritical CO2. Journal of China University of Mining \& Technology 02:319-324.

[13]Kong, W.A. Zheng, S.L. Bai, C.H. \& Dou, Z.L. 2010. Study on Swelling Performance of Bentonite in Aqueous Solution. Non-Metallic Mines 01:42-44.

[14]Robert, J.R. Tamer, K. \& James, L.P. 2005. Experimental Investigation of CO2-brine-rock Interactions at Elevated Temperature and Pressure: Implications for CO2 Sequestration in Deep Saline Aquifers. Fuel Processing Technology 86: 1581-1597. 